\title{
A large geometric distortion in the first photointermediate of rhodopsin, determined by double-quantum solid-state NMR
}

\author{
Maria Concistrè • Ole G. Johannessen • Neville McLean • \\ Petra H. M. Bovee-Geurts • Richard C. D. Brown • \\ Willem J. DeGrip • Malcolm H. Levitt
}

Received: 28 February 2012/ Accepted: 1 May 2012

(C) Springer Science+Business Media B.V. 2012

\begin{abstract}
Double-quantum magic-angle-spinning NMR experiments were performed on $11,12-{ }^{13} \mathrm{C}_{2}$-retinylidenerhodopsin under illumination at low temperature, in order to characterize torsional angle changes at the $\mathrm{C} 11-\mathrm{C} 12$ photoisomerization site. The sample was illuminated in the NMR rotor at low temperature $(\sim 120 \mathrm{~K})$ in order to trap the primary photointermediate, bathorhodopsin. The NMR data are consistent with a strong torsional twist of the $\mathrm{HCCH}$ moiety at the isomerization site. Although the $\mathrm{HCCH}$ torsional twist was determined to be at least $40^{\circ}$, it was not possible to quantify it more closely. The presence of a strong twist is in agreement with previous Raman observations. The energetic implications of this geometric distortion are discussed.
\end{abstract}

Keywords Rhodopsin - Bathorhodopsin - Magic-angle spinning $\cdot$ Double-quantum heteronuclear local field experiment · Double-quantum NMR - Torsional angle estimation

M. Concistrè $(\bowtie) \cdot$ O. G. Johannessen · N. McLean .

R. C. D. Brown - M. H. Levitt

School of Chemistry, University of Southampton,

SO17 1BJ Southampton, UK

e-mail: mariac@soton.ac.uk

M. H. Levitt

e-mail: mhl@soton.ac.uk

O. G. Johannessen

School of Engineering Science, University of Southampton,

Southampton, UK

P. H. M. Bovee-Geurts - W. J. DeGrip

Nijmegen Centre for Molecular Life Sciences, Radboud

University Nijmegen Medical Centre, 6500 HB Nijmegen,

The Netherlands

\section{Introduction}

Rhodopsin is the protein component of the light receptor in the retinal rod cells of the vertebrate eye and is responsible for vision under dim light. It is a $41 \mathrm{kDa}$ membrane protein which consists of a single polypeptide, called opsin, and a 11-Z-retinylidene chromophore, derived by oxidation of vitamin A. Rhodopsin, a prototypical G-protein coupled receptor (GPCR) for signal transduction, passes through a series of photointermediates after light absorption, until the isomerized ligand splits from the opsin protein (Palczewski 2006; Wald 1968). Light sensitivity is provided by the 11-Z-retinylidene chromophore covalently bound to the Lys-296 residue of the protein by a protonated Schiff base (PSB) linkage (Fig. 1a). The signal transduction process is initiated by light absorption that leads to an ultrafast (200 fs) and highly selective isomerization of the chromophore from the initial 11-Z configuration to a distorted all-E configuration (Fig. 1a). The first stable photostate, bathorhodopsin, can be trapped at temperatures below $125 \mathrm{~K}$ (Palczewski 2006) which allows its structure and properties to be studied by low-temperature illumination of rhodopsin. Bathorhodopsin is an energetic molecule that stores about $2 / 3$ of the absorbed photon energy (Palczewski 2006; Wald 1968). The mechanism for storing this large amount of energy, which corresponds to about $134 \pm 12 \mathrm{~kJ} \mathrm{~mol}^{-1}(32 \pm 3 \mathrm{kcal} / \mathrm{mol})$, is not yet completely known. Three different mechanisms have been proposed and widely discussed (Honig et al. 1979; Kukura et al. 2005; Yan et al. 2004; Birge et al. 1998; Nishimura et al. 1997a, b; Kandori and Maeda 1995; Ganter et al. 1988; Rath et al. 1998; Gascon et al. 2006; Schreiber et al. 2006; Rohrig et al. 2004; Schreiber and Buss 2003): electrostatic energy storage by charge separation between the protonated Schiff base and a counterion (most likely 

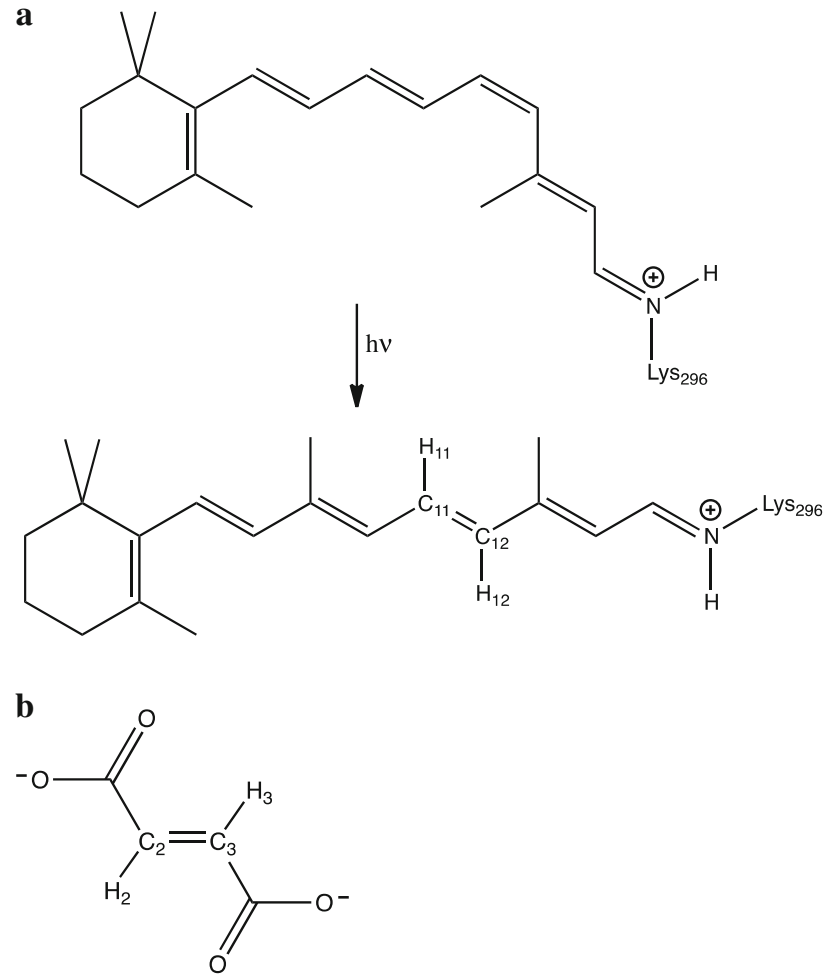

Fig. 1 a The retinylidene chromophore of rhodopsin and its photoinduced cis-trans isomerization. This work used samples labeled with ${ }^{13} \mathrm{C}$ at positions $\mathrm{C} 11$ and $\mathrm{C} 12$. b Molecular structure of the anion in 2,3- ${ }^{13} \mathrm{C}_{2}$-diammonium-fumarate (DAF)

Glu113 or a more extended complex of ions); mechanical energy storage in the form of steric strain energy; and van der Waals interactions between the chromophore and the protein. The first model proposed in 1979 by Honig et al. (1979) considered the charge separation between the negatively charged counterion and the positively charged PSB as the main mechanism. Later Raman studies, however, suggested that intramolecular strain also gives a major contribution to the energy storage (Kukura et al. 2005; Yan et al. 2004). According to calculations by Birge et al. (Birge et al. 1998) about the $60 \%$ of the stored energy can be attributed to strain and the rest of it to electrostatic effects. FT-IR spectroscopy studies (Nishimura et al. 1997a, b; Kandori and Maeda 1995; Ganter et al. 1988; Rath et al. 1998) seem to indicate that a rearrangement of the water network takes place after phoisomerization and this influences the electrostatic forces between the PSB and the counterion. A series of calculations using quantum mechanics/molecular mechanics (QM/MM) (Gascon et al. 2006; Schreiber et al. 2006), molecular dynamics (MD) (Rohrig et al. 2004), and density functional theory (DFT) (Schreiber and Buss 2003) have also been used to assess the relative importance of the three proposed contributions to the energy storage mechanism.
Solid-state NMR can contribute significantly to this debate by providing additional experimental data on the charge distribution and the geometry of the bathorhodopsin chromophore. For example, the chemical shifts of nuclear sites within the chromophore are sensitive to the charge distribution in the unsaturated retinylidene chain. In a previous paper (Concistrè et al. 2008), we used low-temperature $(<120 \mathrm{~K})$ in situ illumination of rhodopsin to isolate and trap bathorhodopsin, and performed doublequantum magic-angle-spinning NMR to isolate the ${ }^{13} \mathrm{C}$ NMR chromophore signals, allowing the ${ }^{13} \mathrm{C}$ chemical shifts in bathorhodopsin to be estimated unambiguously, for the first time. The chemical shift evidence suggests that the electrostatic interaction between the chromophore and the counterion is strongly involved in the energy storage mechanism of bathorhodopsin (Gansmüller et al. 2009). This conclusion was supported by the consistent downfield shifts of the odd-numbered carbon sites in the retinylidene chain, which correlate well with the red shift in the bathorhodopsin optical absorption maximum (Gansmüller et al. 2009). However, the same study showed an unusually large $(9.4 \mathrm{ppm})$ downfield shift for the $\mathrm{C} 10$ resonance which is difficult to explain by charge delocalization effects (see Fig. 1a for the retinylidene carbon numbering scheme). This chemical shift anomaly suggests the simultaneous presence of a geometric distortion in the vicinity of the isomerization site (Gansmüller et al. 2009).

The solid-state NMR technique known as doublequantum heteronuclear local-field spectroscopy can provide direct estimation of the torsional angle in a $\mathrm{H}-\mathrm{C}-\mathrm{C}-\mathrm{H}$ moiety (Feng et al. 1996). This paper reports the results of such an investigation on the $\mathrm{H}-\mathrm{C} 11-\mathrm{C} 12-\mathrm{H}$ moiety in bathorhodopsin. These are the double bonded carbons where photo-isomerization takes place and where a distortion from planarity is most expected if a high degree of steric strain contributes to the storage of light energy. For this purpose rhodopsin was ${ }^{13} \mathrm{C}$-labeled at positions $\mathrm{C} 11$ and $\mathrm{C} 12$ of the retinylidene chain.

The interpretation of the resulting NMR data is quite complicated due to a high degree of spectral overlap between the $\mathrm{C} 11$ and $\mathrm{C} 12$ resonances of bathorhodopsin and those of the rhodopsin molecules that failed to isomerize. Nevertheless, we were able to use a deconvolution technique to extract information on the $\mathrm{H}-\mathrm{C} 11-\mathrm{C} 12-\mathrm{H}$ torsional angle, establishing a deviation from planarity of at least $40^{\circ}$ in bathorhodopsin. These findings agree with previous Raman observations (Kukura et al. 2005; Yan et al. 2004). This strong geometric distortion implies that a significant part of the light energy, used to drive the subsequent protein conformational changes that activate rhodopsin, is stored as steric strain in the bathorhodopsin retinylidene chain. 


\section{Materials and methods}

Samples

Diammonium $2,3-{ }^{13} C_{2}$-fumarate

Diammonium $2,3-{ }^{13} \mathrm{C}_{2}$-fumarate (DAF, see Fig. 1b) was used to validate the double-quantum heteronuclear local field experiment and to provide a benchmark for comparison of the bathorhodopsin data. The $\mathrm{HCCH}$ torsional angle in this compound is known to be exactly $180^{\circ}$ from the crystal structure (Hosomi et al. 1998). The sample of diammonium $2,3-{ }^{13} \mathrm{C}_{2}$-fumarate was purchased from Cambridge Isotopes (Andover, MA, US) and used without modification.

\section{$\left[11,12-{ }^{13} C_{2}\right]$-retinylidene-rhodopsin}

$\left[11,12-{ }^{13} \mathrm{C} 2\right]-11-Z$-retinal was prepared by enantioselective organic synthesis (Groesbeek and Lugtenburg 1992; Lai et al. 2006; McLean et al. 2011). The labeled 11-Z-retinal was incorporated into bovine opsin, isolated from fresh cattle eyes (de Grip et al. 1980). The sample was stored at $-80{ }^{\circ} \mathrm{C}$ and handled under dim red light. The rhodopsin was reconstituted with natural membrane lipids, frozen with liquid nitrogen, ground into small particles, mixed with $\sim 100 \mu \mathrm{m}$ diameter glass beads to maximize the light penetration, and packed into a thin-wall zirconia magicangle-spinning NMR rotor (4 $\mathrm{mm}$ outer-diameter). The characterization of the retinal and rhodopsin samples is described elsewhere (Concistrè et al. 2008).

\section{$\left[11,12-{ }^{13} C_{2}\right]$-retinylidene-bathorhodopsin}

About $30 \%$ of the rhodopsin was converted into bathorhodopsin by illuminating the NMR rotor for $12 \mathrm{~h}$ with filtered light of wavelength $420 \mathrm{~nm}$ at a temperature below $120 \mathrm{~K}$. The NMR probe and illumination conditions are described below.

\section{Apparatus}

\section{NMR probe}

A custom-built $4 \mathrm{~mm}$ MAS NMR probe, designed to allow in situ magic-angle-spinning NMR experiments on an illuminated cold sample, was used. The gas lines were designed to minimize the temperature gradient between the cooling, spinning and bearing gases. Dry nitrogen gas was used for the journal bearings, turbine drive, and sample temperature control.

\section{Illumination}

Light was generated using two $250 \mathrm{~W}$ quartz lamps, filtered through cooled $420 \pm 5 \mathrm{~nm}$ interference filters, and conveyed into the sample region using 14 optical fibres (Concistrè et al. 2008, 2009). As described in Ref. (Concistrè et al. 2009), the use of the glass beads and the choice of illumination wavelength optimizes the yield of bathorhodopsin while minimizing the generation of the undesired isorhodopsin (9-Z) ground state.

The experimental apparatus and the procedures used for sample characterization, temperature control, temperature calibration, and illumination, are described in detail elsewhere (Concistrè et al. 2008).

Experimental procedures

\section{NMR experiments}

All NMR experiments were performed at a magnetic field of $9.4 \mathrm{~T}$ on a Varian Infinity + solid-state NMR spectrometer, using a spinning frequency of $\omega_{\mathrm{r}} / 2 \pi=7,000 \mathrm{~Hz}$ in the rhodopsin case and $\omega_{\mathrm{r}} / 2 \pi=5,600 \mathrm{~Hz}$ for the DAF. The spinning frequency stability was $\pm 50 \mathrm{~Hz}$.

\section{Pulse sequences}

Double-quantum ${ }^{13}$ C spectroscopy The double-quantumfiltered dipolar recoupling pulse sequence used for the selective observation of ${ }^{13} \mathrm{C}$ NMR signals from ${ }^{13} \mathrm{C}_{2}$ pairs is shown in Fig. 2. Cross-polarization of ${ }^{1} \mathrm{H}$ magnetization

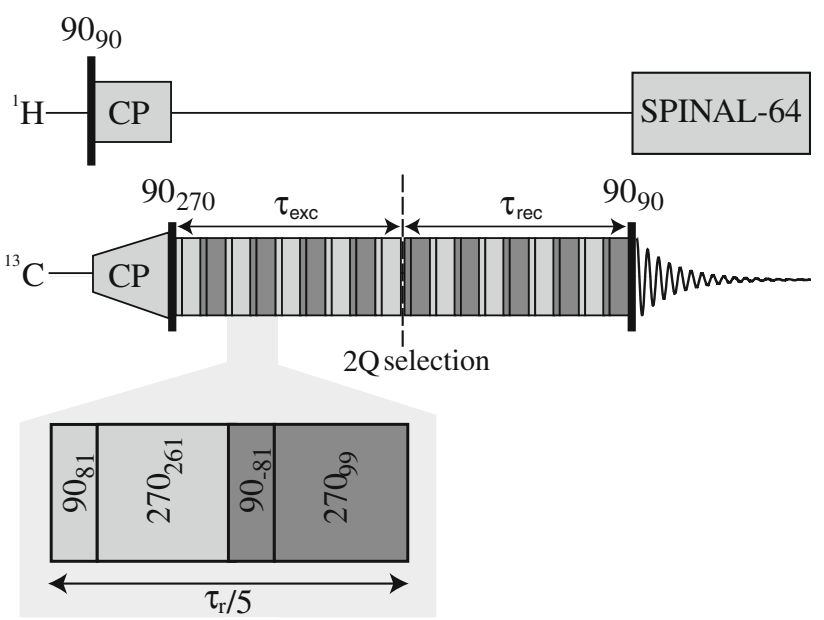

Fig. 2 Pulse sequence used for the double quantum filtered dipolar recoupling experiment. $\tau_{\mathrm{r}}$ is the rotor period, $\tau_{\mathrm{exc}}$ and $\tau_{\mathrm{rec}}$ are the double-quantum excitation and reconversion intervals, respectively. $\mathrm{CP}$ indicates a Cross-Polarization step while SPINAL-64 (Fung et al. 2000) is the decoupling scheme used during signal acquisition. The pulse flip angles and phases (in degrees), and the indicated timing, correspond to the symmetry $\mathrm{R} 20_{2}^{9}$ 
to ${ }^{13} \mathrm{C}$ is followed by excitation of double-quantum ${ }^{13} \mathrm{C}$ coherences by a symmetry-based $\mathrm{R} 20_{2}^{9}$ recoupling sequence (Levitt 2002). The phases of the radiofrequency pulses are shown explicitly in Fig. 2. The double-quantum excitation and reconversion intervals $\left(\tau_{\mathrm{exc}}\right.$ and $\tau_{\text {rec }}$, respectively) were both set equal to $380 \mu$ s to maximize the double-quantum efficiency. No radiofrequency field was applied on the ${ }^{1} \mathrm{H}$ channel during the $\mathrm{R} 20_{2}^{9}$ recoupling sequence since the high-power ${ }^{13} \mathrm{C}$ rf field $(70 \mathrm{kHz}$ in the present case) achieved sufficient heteronuclear decoupling (Marin-Montesinos et al. 2005). A SPINAL-64 (Fung et al. 2000) decoupling sequence was applied on the ${ }^{1} \mathrm{H}$ channel during detection of the ${ }^{13} \mathrm{C}$ free induction decay. Doublequantum filtering was achieved using a 16-step phase cycle (Levitt 2008).

2Q-HLF experiments The 2Q-HLF experiment for estimating the $\mathrm{HCCH}$ torsional angle is discussed in Ref. (Feng et al. 1996) and (Brinkmann 2001). The pulse sequence is shown in Fig. 3. The experiment involves the following steps: (i) a double-quantum state involving the two ${ }^{13} \mathrm{C}$ sites is prepared using cross-polarization followed by a double-quantum (2Q) homonuclear dipolar recoupling sequence of symmetry R 202 (Levitt 2002); (ii) the $2 \mathrm{Q}^{13} \mathrm{C}_{2}$ coherence evolves for one rotor period $\tau_{\mathrm{r}}=\mid 2 \pi / \omega_{\mathrm{r}} \mathrm{l}$, where $\omega_{\mathrm{r}} / 2 \pi$ is the spinning frequency in $\mathrm{Hz}$, followed by a $\pi$-pulse for refocusing the ${ }^{13} \mathrm{C}$ chemical shift evolution, and

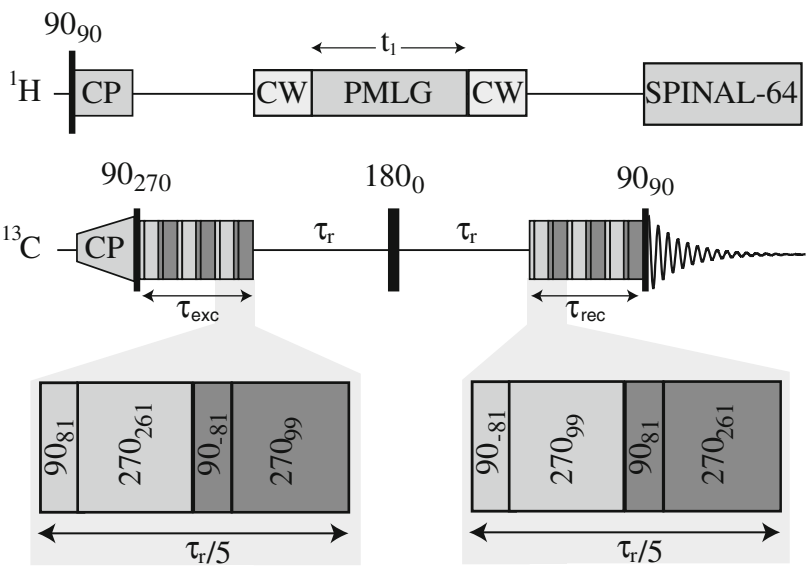

Fig. 3 The 2Q-HLF pulse sequence used for torsional angle measurements. $\tau_{\mathrm{r}}$ is the rotor period; $\tau_{\mathrm{exc}}$ and $\tau_{\mathrm{rec}}$ are the doublequantum excitation and reconversion intervals, respectively. A PhaseModulated Lee-Goldburg (PMLG) scheme (Vinogradov et al. 1999, 2002) is used for homonuclear decoupling during $t_{1}$ while continuous decoupling $(\mathrm{CW})$ was used during the interval $\tau_{\mathrm{r}}-t_{1}$. CP indicates Cross-Polarization and SPINAL-64 (Fung et al. 2000) is the decoupling scheme used during signal acquisition. The pulse flip angles and phases (in degrees), and indicated timing, correspond to the symmetries $\mathrm{R} 20_{2}^{9}$ (for double-quantum excitation) and $\mathrm{R} 2 \mathrm{O}_{2}^{-9}$ (for double-quantum reconversion) a second rotor period $\tau_{\mathrm{r}}$. A proton homonuclear decoupling sequence of variable duration $t_{1}$ is simultaneously applied during this interval (see below); (iii) the $2 \mathrm{Q}$ coherence is converted back into observable signal by a second recoupling sequence, with symmetry $\mathrm{R}_{2} \mathrm{O}_{2}^{-9}$. The change in sign of the winding number for the second recoupling sequence takes into account the phase inversion induced by the central $\pi$ pulse. The $\tau_{\text {exc }}$ and $\tau_{\text {rec }}$ recoupling intervals were both set to $380 \mu \mathrm{s}$ to maximize the double-quantum efficiency.

A Phase-Modulated-Lee-Goldburg (PMLG) homonuclear decoupling scheme (Vinogradov et al. 1999, 2002) was applied to remove proton-proton dipolar couplings during the variable evolution interval, which consists of two equal intervals $t_{1} / 2$, one before and one after the ${ }^{13} \mathrm{C} \pi$ pulse. The duration of each the $t_{1} / 2$ half-intervals was incremented stepwise from 0 to a full rotor period. In practice we used a PMLG-5 pulse scheme that comprises ten radiofrequency pulses of flip angle $\pi / 2$ and equal duration $\tau_{\mathrm{p}}$ (Paul et al. 2009). For the DAF experiments, 8 increments were fitted into a single rotor period $\tau_{\mathrm{r}}=178.6 \mu \mathrm{s}$ (spinning speed 5,600 Hz) using the PMLG5 pulse duration $\tau_{\mathrm{p}}=2.55 \mu \mathrm{s}$. For the bathorhodopsin experiments, 7 increments were fitted into a rotor period $\tau_{\mathrm{r}}=142.8 \mu$ s (spinning speed 7,000 Hz) using a PMLG-5 pulse duration of $\tau_{\mathrm{p}}=2.38 \mu \mathrm{s}$. Unmodulated ("continuous-wave", $\mathrm{CW}$ ) decoupling was applied on the proton channel during the two intervals $\tau_{\mathrm{r}}-t_{1} / 2$ in order to decouple the heteronuclear ${ }^{13} \mathrm{C}-{ }^{1} \mathrm{H}$ and homonuclear ${ }^{1} \mathrm{H}-{ }^{1} \mathrm{H}$ interactions.

\section{Simulations}

Numerical simulations of the double-quantum signal as a function of the evolution interval $t_{1}$ were performed using SIMPSON (Bak et al. 2000), assuming a regular geometry for the $\mathrm{HCCH}$ fragment $\left[\mathrm{r}_{\mathrm{CC}}=1.34 \AA\right.$ (Feng et al. 1996); $\left.r_{\mathrm{CH}}=1.1 \AA ; \quad \theta_{\mathrm{CCH}}=120^{\circ}\right]$. The simulations involved the local system of two protons and two ${ }^{13} \mathrm{C}$ nuclei, including all dipolar couplings within the fourspin-1/2 system. The simulation parameters for the case of a $\mathrm{HCCH}$ torsional angle of $\phi=180^{\circ}$ are reported in Table 1 (for DAF) and Table 2 (for bathorhodopsin). The SIMPSON simulations did not include relaxation. Damping due to relaxation was added afterwards in a simplified way as explained below.

Simulations were repeated for a set of torsional angles $\phi$ varying between 0 and $180^{\circ}$ in $10^{\circ}$ steps. The spin system parameters for torsional angles other than $180^{\circ}$ were generated by varying $\phi$ while keeping the molecular bond lengths and angles fixed, and deriving new sets of nuclear coordinates, from which the dipolar coupling tensors were calculated. All chemical shift tensors were kept fixed with 
Table 1 Chemical shift, coupling and other parameters used in the SIMPSON simulations of DAF

\begin{tabular}{llcll}
\hline $\begin{array}{l}\text { Chemical } \\
\text { shift }\end{array}$ & $\begin{array}{l}\delta^{l \sigma o} \\
(\mathrm{ppm})\end{array}$ & $\begin{array}{l}\delta^{\mathrm{a} \iota \sigma o} \\
(\mathrm{ppm})\end{array}$ & $\begin{array}{l}\left(\alpha_{P M}^{C S}, \beta_{P M}^{C S}, \gamma_{P M}^{C S}\right) \\
\left({ }^{\circ}\right)\end{array}$ \\
\hline $\mathrm{C} 2$ & $0^{*}$ & $94^{\mathrm{a}}$ & $0.59^{\mathrm{a}}$ & $(-65,102,9)^{\mathrm{a}}$ \\
$\mathrm{C} 3$ & $0^{*}$ & $94^{\mathrm{a}}$ & $0.59^{\mathrm{a}}$ & $(-65,-102,9)^{\mathrm{a}}$ \\
$\mathrm{H} 3$ & $0^{*}$ & $0^{*}$ & $0^{*}$ & $(0,0,0)^{*}$ \\
$\mathrm{H} 4$ & $0^{*}$ & $0^{*}$ & $0^{*}$ & $(0,0,0)^{*}$ \\
\hline Coupling & $\mathrm{J}(\mathrm{Hz})$ & $\mathrm{b} /(2 \pi \mathrm{kH})$ & $\left(\alpha_{P M}^{D D}, \beta_{P M}^{D D}, \gamma_{P M}^{D D}\right)\left(^{\circ}\right)$ \\
\hline $\mathrm{C} 2-\mathrm{C} 3$ & $68^{\mathrm{a}}$ & $-3.350^{\mathrm{a}}$ & $(0,0,0)^{\mathrm{a}}$ \\
$\mathrm{C} 2-\mathrm{H} 3$ & $0^{*}$ & $-3.293^{\mathrm{b}}$ & $(-180,27.1,-180)^{\mathrm{b}}$ \\
$\mathrm{C} 2-\mathrm{H} 2$ & $0^{*}$ & $-22.698^{\mathrm{b}}$ & $(-180,120,0)^{\mathrm{b}}$ \\
$\mathrm{C} 3-\mathrm{H} 3$ & $0^{*}$ & $-22.698^{\mathrm{b}}$ & $(-180,60,-180)^{\mathrm{b}}$ \\
$\mathrm{C} 3-\mathrm{H} 2$ & $0^{*}$ & $-3.293^{\mathrm{b}}$ & $(-180,153.9,0)^{\mathrm{b}}$ \\
$\mathrm{H} 2-\mathrm{H} 3$ & $0^{*}$ & $-4.130^{\mathrm{b}}$ & $(-180,141.7,0)^{\mathrm{b}}$
\end{tabular}

Other parameters

\begin{tabular}{ll}
\hline $\mathrm{B}_{0}(\mathrm{~T})$ & 9.39 \\
$\omega_{\mathrm{r}} /(2 \pi)(\mathrm{kHz})$ & 5.6 \\
$\omega_{\text {nut }}^{H} /(2 \pi)(\mathrm{kHz})$ & 76.5 \\
$\omega_{\text {nut }}^{c} /(2 \pi)(\mathrm{kHz})$ & 71.2 \\
Crystal File & REP256 \\
$\gamma$ angles & 20
\end{tabular}

$\overline{\delta^{l \sigma o}}$ is the isotropic chemical shift, $\delta^{\text {ani } \sigma o}$, the chemical shift anisotropy, $\eta$ is the chemical shift biaxiality parameter and $\left(\alpha_{P M}^{C S}, \beta_{P M}^{C S}, \gamma_{P M}^{C S}\right)$ are the Euler angles that relate the principal axes of the chemical shift tensor to the molecular frame chose with is $z$-axis along the $\mathrm{C} 2-\mathrm{C} 3$ bond and its $y$-axis perpendicular to the $\mathrm{HCCH}$ plane. The isotropic chemical shifts are specified relative to the experimental carrier frequency. $\mathbf{J}$ is the indirect spin-spin coupling constant, $\mathrm{b}$ is the dipolar coupling constant (in $\left.\operatorname{rad~s}^{-1}\right)$ and $\left(\alpha_{P M}^{D D}, \beta_{P M}^{D D}, \gamma_{P M}^{D D}\right)$ are the Euler angles that relate the principal axes of the dipolar coupling tensor to the molecular frame. $\mathrm{B}_{0}$ is the strength of the magnetic field, $\omega_{\mathrm{r}}$ is the spinning frequency, $\omega_{n u t}^{H}$ is the nutation frequency on the proton channel and $\omega_{\text {nut }}^{c}$ is the nutation frequency on the carbon-13 channel.* Assumed. ${ }^{\mathrm{a}}$ Ref. (Carravetta et al. 2001). ${ }^{\mathrm{b}}$ values calculated for $\mathrm{r}_{\mathrm{CC}}=1.34 \AA$ (Feng et al. 1996), $\mathrm{r}_{\mathrm{CH}}=1.1 \AA$ and $\theta_{\mathrm{CCH}}=120^{\circ}$

respect to the local molecular groups. A Mathematica program (Wolfram Research Inc 2010) was used to generate the nuclear coordinates as a function of $\phi$ and to derive the Euler angle sets describing the tensor orientations.

The validity of the numerical simulations is limited by the uncertainties in some of the assumed parameters, such as the bond lengths, bond angles, and chemical shift tensors, and the effects of magnetic nuclei outside the local 4-spin system. Simulations show that the pulse sequences are robust with respect to reasonable deviations in the chemical shift tensors, so this source of uncertainty may be discounted. The influence of geometrical uncertainties is more significant and is discussed further below.
Table 2 Chemical shift, coupling and other parameters used in SIMPSON simulations in the case of bathorhodospin, assuming perfect all-trans geometry $\left(\phi=180^{\circ}\right)$

\begin{tabular}{lcccl}
\hline $\begin{array}{l}\text { Chemical } \\
\text { shift }\end{array}$ & $\begin{array}{c}\delta^{l \sigma o} \\
(\mathrm{ppm})\end{array}$ & $\begin{array}{c}\delta^{\mathrm{an} \imath \sigma o} \\
(\mathrm{ppm})\end{array}$ & $\eta$ & $\begin{array}{l}\left(\alpha_{P M}^{C S}, \beta_{P M}^{C S}, \gamma_{P M}^{C S}\right) \\
\left({ }^{\circ}\right)\end{array}$ \\
\hline $\mathrm{C} 11$ & $5.8^{+}$ & $-101.5^{\mathrm{a}}$ & $0.78^{\mathrm{a}}$ & $(0,0,0)^{\mathrm{a}}$ \\
$\mathrm{C} 12$ & $-5.8^{+}$ & $81.7^{\mathrm{a}}$ & $0.93^{\mathrm{a}}$ & $(0,0,0)^{\mathrm{a}}$ \\
$\mathrm{H} 11$ & $0^{*}$ & $0^{*}$ & $0^{*}$ & $(0,0,0)^{*}$ \\
$\mathrm{H} 12$ & $0^{*}$ & $0^{*}$ & $0^{*}$ & $(0,0,0)^{*}$ \\
\hline Coupling & $\mathrm{J}(\mathrm{Hz})$ & $\mathrm{b} / 2 \pi^{*}(\mathrm{kHz})$ & $\left(\alpha_{P M}^{D D}, \beta_{P M}^{D D}, \gamma_{P M}^{D D}\right)\left(^{\circ}\right)$ \\
\hline $\mathrm{C} 11-\mathrm{C} 12$ & $0^{*}$ & $-3.166^{\mathrm{a}}$ & $(0,0,0)^{\mathrm{a}}$ \\
$\mathrm{C} 11-\mathrm{H} 11$ & $0^{*}$ & $-22.698^{\mathrm{b}}$ & $(-180,120,0)^{\mathrm{b}}$ \\
$\mathrm{C} 11-\mathrm{H} 12$ & $0^{*}$ & $-3.186^{\mathrm{b}}$ & $(-180,26.7,-180)^{\mathrm{b}}$ \\
$\mathrm{C} 12-\mathrm{H} 11$ & $0^{*}$ & $-3.186^{\mathrm{b}}$ & $(-180,153.3,0)^{\mathrm{b}}$ \\
$\mathrm{C} 12-\mathrm{H} 12$ & $0^{*}$ & $-22.698^{\mathrm{b}}$ & $(-180,60,-180)^{\mathrm{b}}$ \\
$\mathrm{H} 11-\mathrm{H} 12$ & $0^{*}$ & $-4.049^{\mathrm{b}}$ & $(-180,38,-180)^{\mathrm{b}}$ \\
\hline Other parameters & & \\
\hline $\mathrm{B}_{0}(\mathrm{~T})$ & & 9.39 & \\
$\omega_{\mathrm{r}} /(2 \pi)(\mathrm{kHz})$ & 7.0 & \\
$\omega_{\text {nut }}^{H} /(2 \pi)(\mathrm{kHz})$ & 78.8 & \\
$\omega_{\text {nut }}^{c} /(2 \pi)(\mathrm{kHz})$ & 78.8 & \\
$\mathrm{Crystal} \mathrm{file}$ & & $\mathrm{REP} 2000$ & \\
$\gamma$ angles & & 30 & \\
\hline
\end{tabular}

$\delta^{l \sigma o}$ is the isotropic chemical shift, $\delta^{\text {ani } \sigma o}$, the chemical shift anisotropy, $\eta$ is the chemical shift biaxiality and $\left(\alpha_{P M}^{C S}, \beta_{P M}^{C S}, \gamma_{P M}^{C S}\right)$ are the Euler angles that relate the principal axes of the chemical shift tensor to the molecular frame chose with is $z$-axis along the $\mathrm{C} 11-\mathrm{C} 12$ bond and its $y$-axis perpendicular to the $\mathrm{HCCH}$ plane. The isotropic chemical shifts are specified relative to the experimental carrier frequency. $J$ is the indirect spin-spin coupling value (here neglected). $b$ is the dipolar coupling constant (in units of $\mathrm{rad} \mathrm{s}^{-1}$ ) and $\left(\alpha_{P M}^{D D}, \beta_{P M}^{D D}, \gamma_{P M}^{D D}\right)$ are the Euler angles that relate the principal axes of the dipolar coupling tensor to the molecular frame. $\mathrm{B}_{0}$ is the strength of the magnetic field, $\omega_{\mathrm{r}}$ is the spinning frequency, $\omega_{n u t}^{H}$ is the nutation frequency on the proton channel and $\omega_{n u t}^{c}$ is the nutation frequency on the carbon channel. ${ }^{+}$Ref. (Concistrè et al. 2008) *Assumed. ${ }^{a}$ Assumed equal to the rhodopsin case in Ref. (Carravetta et al. 2001). balues calculated assuming $\mathrm{r}_{\mathrm{CC}}=1.34 \AA$ (Feng et al. 1996), $\mathrm{r}_{\mathrm{CH}}=1.1 \AA$ and $\theta_{\mathrm{CCH}}=120^{\circ}$

Peak amplitude estimation

Diammonium 2,3- ${ }^{13} \mathrm{C}_{2}$-fumarate

The determination of torsional angle requires the estimation of the double-quantum-filtered peak amplitudes for a series of evolution intervals $t_{1}$, and comparison with numerical simulations. In the case of DAF, the good signalto-noise ratio and the presence of a single resonance peak in the spectrum, allow the integrated spectral amplitudes $I\left(t_{1}\right)$ to be used directly. 


\section{$\left[11,12-{ }^{13} C_{2}\right]$-retinylidene-bathorhodopsin}

The estimation of the bathorhodopsin spectral amplitudes is considerably more challenging, since the signal-to-noise ratio is limited, even after considerable signal averaging, and there is a great deal of overlap between the $\mathrm{C} 11$ peaks of bathorhodopsin and non-isomerized rhodopsin. In the case of $\mathrm{C} 12$ the situation is even worse, with the peaks of the two species overlapping completely (see Fig. 4).

The following procedure was used to estimate the bathorhodopsin spectral amplitude as a function of $t_{1}$, and its confidence limits, in the presence of strong overlap with the rhodopsin peaks. Two different spectral masking functions were constructed, one for bathorhodopsin and one for rhodopsin, denoted $S_{B}^{M}(\omega)$ and $S_{R}^{M}(\omega)$ respectively. The masking functions for the species $X \in(R, B)$ are defined to have unit integral, and consist of sums of Lorentzian peaks, with peak frequencies $\omega_{\mathrm{X}}^{j}$, relative peak amplitudes $a_{\mathrm{X}}^{j}$ and peak halfwidths-at-half-height $\lambda_{X}$ matching the observed ${ }^{13} \mathrm{C}$ peaks of the corresponding species in the $t_{1}=0$ spectrum (including both the $\mathrm{C} 11$ and C12 centrebands)

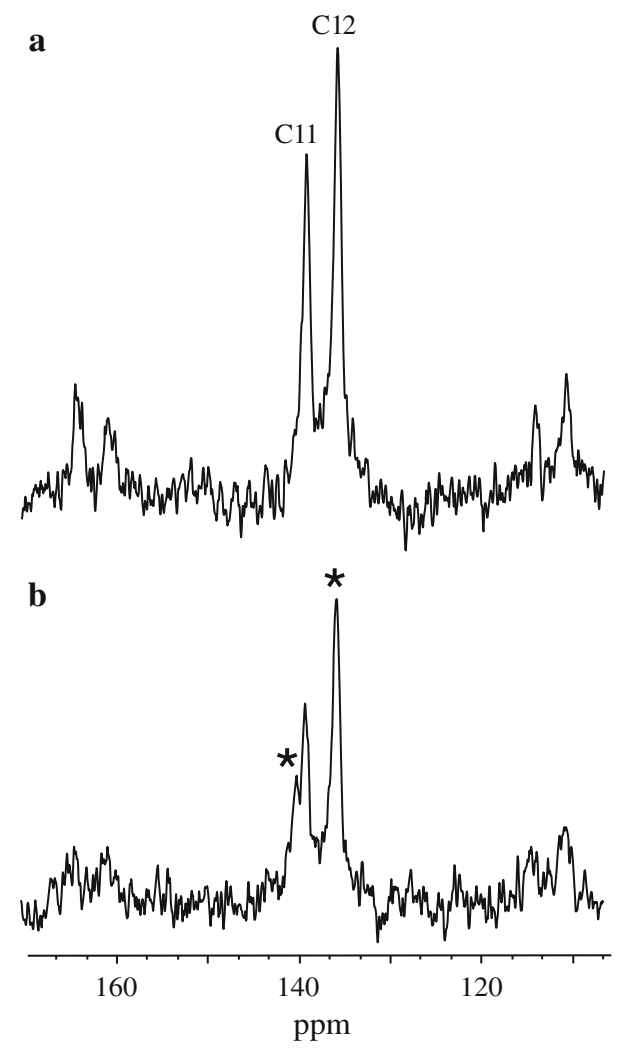

Fig. 4 Double quantum spectrum of $\left[11,12-{ }^{13} \mathrm{C}_{2}\right]$-retinilydene-rhodopsin a before and $\mathbf{b}$ after continuous illumination for $12 \mathrm{~h}$ at $420 \mathrm{~nm}$ and 120 Kelvin. The spectra are the sum of 6144 signal transients using a MAS frequency of $7.00 \pm 0.05 \mathrm{kHz}$. Both spectra were acquired at a sample temperature of 120 Kelvin. The positions of the bathorhodopsin peaks are indicated by asterisks
$S_{X}^{M}(\omega)=\sum_{j} \frac{a_{X}^{j}}{\lambda_{X}-i\left(\omega-\omega_{X}^{j}\right)}$

where $\sum_{j} a_{x}^{j}=1$

The overlap matrix between the masking functions for bathorhodopsin and rhodopsin is calculated as follows:

$\mathrm{L}=\left(\begin{array}{ll}L_{B B} & L_{B R} \\ L_{R B} & L_{R R}\end{array}\right)$

where by definition

$L_{B B}=L_{R R}=1$

and the overlap integrals are defined as follows:

$L_{B R}=L_{R B}^{*}=\int_{-\infty}^{+\infty} S_{B}^{M}(\omega)^{*} S_{R}^{M}(\omega) d \omega$

In the experiments described here, the overlap integrals were determined numerically to be $L_{B R}=L_{R B}^{*}=0.26$.

Suppose that experimental spectra $S^{\exp }\left(\omega, t_{1}\right)$ are obtained for each evolution interval $t_{1}$. A rough estimate of the spectral intensities for the two species is given by integrating the products of the spectral masking functions for the two species by the experimental spectra:

$c_{X}\left(t_{1}\right)=\int_{-\infty}^{+\infty} S_{X}^{M}(\omega)^{*} S^{\exp }\left(\omega, t_{1}\right) d \omega$

where $X \in(R, B)$. These rough intensity estimates may be assembled into a 2-component vector:

$c\left(t_{1}\right)=\left(\begin{array}{l}c_{B}\left(t_{1}\right) \\ c_{R}\left(t_{1}\right)\end{array}\right)$

The true intensities of the $\mathrm{B}$ and $\mathrm{R}$ signals at time point $t_{1}$ are estimated by applying the inverse of the overlap matrix to the vector $\mathbf{c}\left(t_{1}\right)$ :

$\mathrm{I}\left(t_{1}\right)=\left(\begin{array}{l}a_{B}\left(t_{1}\right) \\ a_{R}\left(t_{1}\right)\end{array}\right)=L^{-1} c\left(t_{1}\right)$

The elements $I_{B}\left(t_{1}\right)$ of the intensity vector provide estimates of the signal intensities, corrected for peak overlap, and with optimal use of the available signal. These signal intensity estimates are used in the analysis of the bathorhodopsin torsional angle.

Note that for complete peak overlap, the overlap matrix is singular and cannot be inverted. The confidence limits on $I_{B}\left(t_{1}\right)$ were estimated by shifting the masking function $S_{B}^{M}$ $(\omega)$ to a signal-free region of the spectrum, obtaining an amplitude estimate, and repeating 50 times using a different signal-free spectral region each time. The confidence limits were set equal to the standard deviation $\sigma$ of the 50 samples. 
Torsional Angle Estimation

To obtain an estimate of the $\mathrm{H}-\mathrm{C}-\mathrm{C}-\mathrm{H}$ torsional angle $\phi$, and its confidence limits, the experimental signal amplitudes $I\left(t_{1}\right)$ were compared to numerical simulations as a function of torsional angle $\phi$ obtained using the parameters given in Table 1 (for DAF) and Table 2 (for bathorhodopsin).

For each torsional angle value, the simulated amplitudes $I^{\operatorname{sim}}\left(\phi, t_{1}\right)$ were multiplied by a vertical scale factor and an exponential damping function in order to include the effects of enhanced spin dephasing occurring during the PMLG sequences:

$I^{s i m}\left(\phi, t_{1}\right)^{\prime}=k_{f i t}(\phi) \exp \left\{-\lambda_{f i t}(\phi) t_{1}\right\} \times I^{s i m}\left(\phi, t_{1}\right)$

The parameters $k_{f i t}(\phi)$ and $\lambda_{f i t}(\phi)$ were optimized numerically at each torsional angle to minimize the mean-square deviation between the experimental set of points $I\left(t_{1}\right)$ and the simulated best-fit points $I^{\operatorname{sim}}\left(\phi, t_{1}\right)^{\prime}$.

The $\chi^{2}$ statistic was calculated for each torsional angle $\phi$ by summing the mean-square-deviations between experiment and simulation for each $t_{1}$ point, and dividing by the squared confidence limits $\sigma_{i}^{2}$ on the signal intensities for each point:

$\chi^{2}=\sum_{i} \frac{\left\{I_{i}\left(t_{1}\right)-I^{\operatorname{sim}}\left(\phi, t_{1}\right)^{\prime}\right\}^{2}}{\sigma^{2}}$

A plot of $\chi^{2}(\phi)$ against $\phi$ displays a minimum value $\chi_{\text {min. }}^{2}$. The confidence limits on the torsional angle determination may be estimated from the region of torsional angles for which $\chi^{2}(\phi)$ is less than or equal to $\chi_{\min }^{2}+1$ (Numerical Recipes in C. The art of scientific computing, 2nd Edn 1992).

\section{Results}

Diammonium $2,3-{ }^{13} \mathrm{C}_{2}$-fumarate

Figure 5a shows the signal intensities $I\left(t_{1}\right)$ obtained for a sample of DAF using the pulse sequence in Fig. 3. Eight points were collected by equal increments of $t_{1}$ from 0 to $2 \tau_{\mathrm{r}}$. Each point is the sum of 64 transients. The experimental points are well-fitted by numerical simulations using the parameters in Table 1 with $\phi=170^{\circ}$ or $\phi$ $=175^{\circ}$ for the torsional angle $\mathrm{HCCH}$.

The $\chi^{2}$ analysis of DAF is reported in Fig. 6a. Only a narrow range of torsional angles $\phi$ between $170^{\circ}$ and $175^{\circ}$ fall within one standard deviation from the minimum.

In practice the fumarate dianion is exactly planar $(\phi$ $=180^{\circ}$ ), so there is a small discrepancy of about $5^{\circ}$ between the determined torsional angle and the correct result. The same discrepancy has been noted before
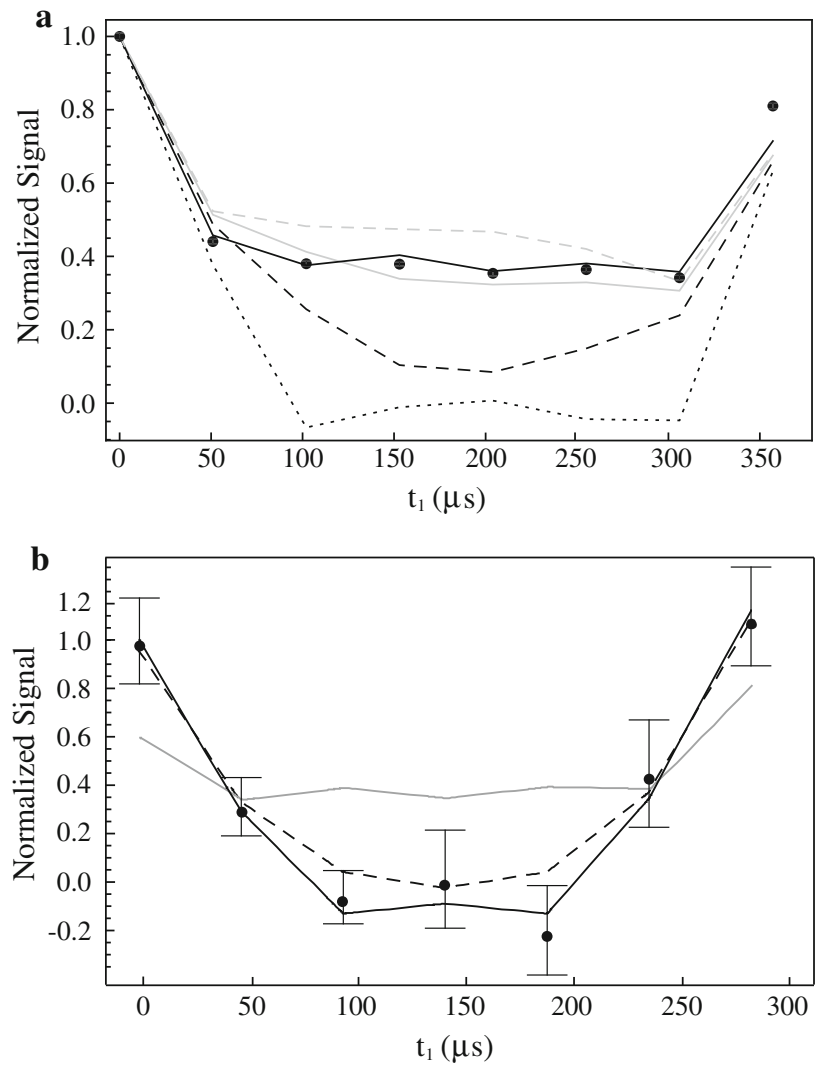

Fig. 5 a Experimental double quantum signal amplitudes (circles) as a function of $t_{1}$ obtained for DAF using the pulse sequence in Fig. 3. Lines represent numerical simulations with $\phi$ equal to $0^{\circ}$ (dotted black), $160^{\circ}$ (dashed black), $170^{\circ}$ (solid grey), $175^{\circ}$ (solid black) and $180^{\circ}$ (dashed grey). Error bars fall within the point size. b Experimental signal intensities (circles) and error bars as a function of $t_{1}$ in the case of bathorhodopsin and compared with numerical simulations (lines) for $\phi=0^{\circ}$ (solid black), $\phi=140^{\circ}$ (dashed black) and $\phi=180^{\circ}$ (solid grey)

(Brinkmann 2001). Since the modulation curves are extremely sensitive in this range of $\phi$, the small discrepancy could be due to numerous factors, for example the presence of $r f$ inhomogeneity, non-uniform cross-polarization, or the influence of remote spins outside the local $\mathrm{H}-$ C-C-H moiety (Brinkmann 2001). The influence of such factors, in any possible combination, is also visible in the incomplete refocusing observed at $t_{1}=2 \tau_{\mathrm{r}}$ (see Fig. 5). A precise explanation is not yet available.

\section{Bathorhodopsin}

\section{Double-Quantum filtered experiment}

Figure 4 shows DQ-filtered ${ }^{13} \mathrm{C}$ spectra of $11,12-{ }^{13} \mathrm{C}_{2}$-retinylidene rhodopsin, acquired using the pulse sequence in Fig. 3, before (a) and after (b) illumination. Both spectra are the averages of 6144 signal transients. The leftmost peak on the top spectrum belongs to the C11 site of 

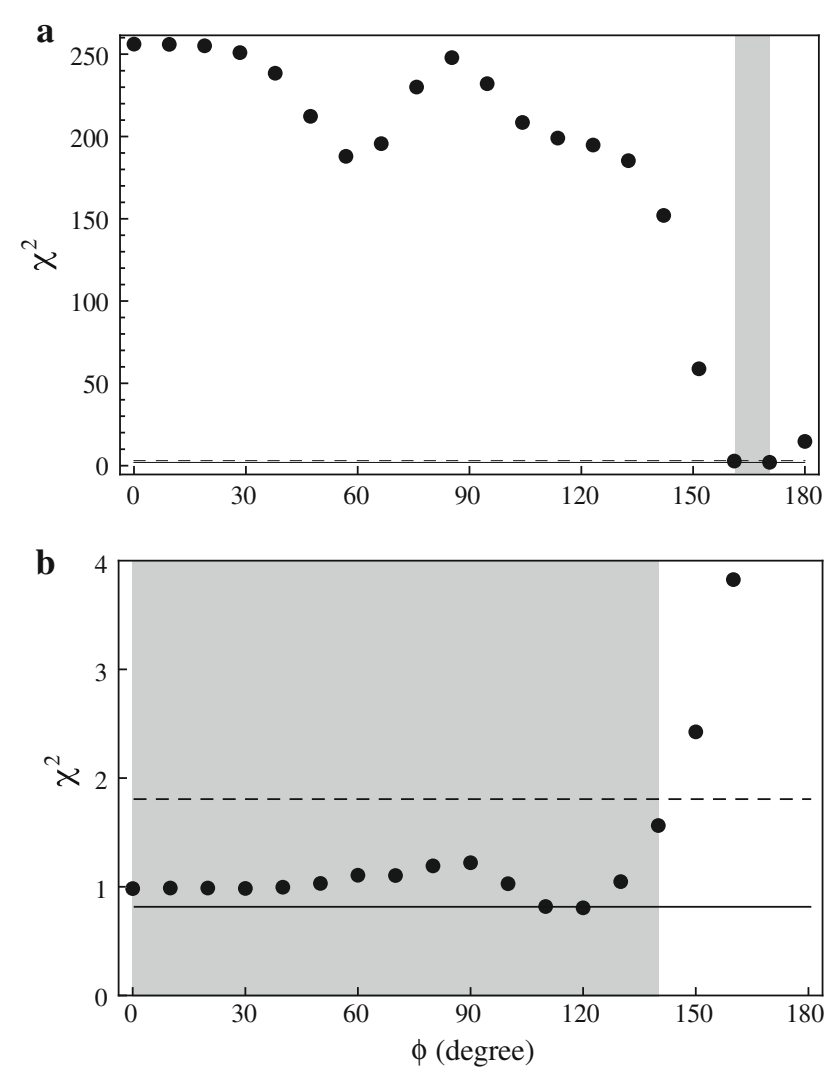

Fig. 6 Chi-square $\left(\chi^{2}\right)$ values (calculated from Eq. 1) plotted versus the torsional angle $\phi$ in the case of DAF (a) and bathorhodopsin (b). The solid and dashed line indicates the value of and +1 , respectively Rough $68 \%$ confidence limits on the parameter $\phi$ may be estimated from the bounds of the region (The angles falling in that regions are shaded in light grey)

rhodopsin, whose chemical shift was determined to be $\delta_{\text {iso }}=141.4 \mathrm{ppm}$ (Creemers et al. 2002). The rightmost peak, at $\delta_{\text {iso }}=131.8 \mathrm{ppm}$, is attributed to the $\mathrm{C} 12$ site (Creemers et al. 2002). The double-quantum-filtering efficiency was about $35 \%$.

After illumination, a new peak appears at $144.4 \mathrm{ppm}$. The evident decrease in intensity of the $141.4 \mathrm{ppm}$ retinylidene-C11 peak in the spectrum acquired after sample illumination indicates that this new peak belongs to the retinylidene-C11 site of bathorhodopsin. The $\mathrm{C} 12$ peaks of rhodopsin and bathorhodopsin are not spectrally resolved since they have very close ${ }^{13} \mathrm{C}$ chemical shift (less than $1 \mathrm{ppm}$ difference). The bathorhodopsin chemical shifts are consistent with previous experiments on different ${ }^{13} \mathrm{C}_{2}$-isotopomers (Concistrè et al. 2008).

\section{Double-Quantum Heteronuclear Local Field experiment}

The pulse sequence in Fig. 3 was applied to the illuminated sample. Seven experimental points were acquired obtained by equal increments of $t_{1}$ from 0 to $2_{\mathrm{r}}$. Each point is the sum of 5632 transients.
Figure $5 \mathrm{~b}$ shows the overlap-corrected experimental peak intensities for bathorhodopsin $I_{B}\left(t_{1}\right)$ (filled circles) as a function of the evolution interval $t_{1}$. The error bars on the points indicate the confidence limits $\sigma_{i}$, which take into account the relatively poor signal-to-noise ratio as well as the strong overlap with the rhodopsin peaks.

The plotted lines join points $I^{\text {sim }}\left(\phi, t_{1}\right)^{\prime}$ obtained by best-fit numerical simulations using values of $0^{\circ}$ (solid black), $140^{\circ}$ (dotted) and $180^{\circ}$ (solid grey) for the H-C11$\mathrm{C} 12-\mathrm{H}$ torsional angle. The experimental points are reasonably well fitted for a wide range of $\phi$ values spanning from $0^{\circ}$ to $140^{\circ}$, but the exact trans geometry $\left(\phi=180^{\circ}\right)$ is clearly a poor fit.

The $\chi^{2}$ plot shown in Fig. $6 \mathrm{~b}$ makes the same point with more rigour. Although any torsional angle between $0^{\circ}$ to $140^{\circ}$ is consistent with the experimental data (as shown by the grey region), this result in principle implies a deviation from planarity of at least $40^{\circ}$ around the $\mathrm{C} 11=\mathrm{C} 12$ double bond in bathorhodopsin.

One word of caution must be sounded: The analysis, as formulated above, only considered structural models in which the $\mathrm{H}-\mathrm{C}-\mathrm{C}-\mathrm{H}$ retains canonical bond angles and lengths as the torsional angle is changed. In addition, the $\mathrm{H}-\mathrm{C} 11-\mathrm{C} 12-\mathrm{H}$ torsional angle may not always be directly related to the structurally more informative $\mathrm{C} 10-\mathrm{C} 11-$ $\mathrm{C} 12-\mathrm{C} 13$ torsional angle. In practice, modulation curves corresponding to a $40^{\circ}$ deviation from $\mathrm{H}-\mathrm{C}-\mathrm{C}-\mathrm{H}$ planarity might also be consistent with a variety of other geometric distortions, including a strong change in bond angles, an asymmetry in the two $\mathrm{H}-\mathrm{C}$ bond lengths, and so on. In addition, our analysis ignores vibrations and other molecular dynamic modes that could influence the data. A rigorous conclusion is that the $\mathrm{H}-\mathrm{C} 11-\mathrm{C} 12-\mathrm{H}$ moiety in bathorhodopsin displays a strong deviation from the canonical geometry of a planar all-trans $\mathrm{H}-\mathrm{C}-\mathrm{C}-\mathrm{H}$ group such as that found in fumarate. However the exact nature of the geometrical distortion cannot be determined from the NMR data alone.

\section{Discussion}

The evidence of a strong geometric distortion at the C11-C12 site in bathorhodopsin strengthens the hypothesis that geometric strain contributes to the storage of a significant fraction of the absorbed photon energy. How much energy is stored this way?

An estimate of the amount of energy stored through geometric strain might be achieved by quantum-mechanical techniques. Although such a calculation is beyond the scope of this work, some brief comments may be appropriate. A crude potential energy surface calculation run on the isolated retinal chromophore showed that about 
$67 \mathrm{~kJ} \mathrm{~mol}^{-1}(16 \mathrm{kcal} / \mathrm{mol})$ are stored in a $40^{\circ}$ twist about the $\mathrm{C} 11-\mathrm{C} 12$ bond. These calculations were run using Gaussian09 (Gaussian et al. 2009), optimizing the geometry of the all-trans-conformation using DFT theory (B3LYP functional, 6-31G* basis set) and then changing the torsional angle to a new value (without re-optimization of the geometry) and calculating the energy for this new conformation. These calculations are clearly only indicative since the whole protein has been neglected. Nevertheless, more sophisticated quantum mechanical calculations do agree with cis-trans isomerization of the protein-bound chromophore leading to a highly strained all-trans-conformer in bathorhodopsin (Gascon et al. 2006; Bifone et al. 1997; Frutos et al. 2007; Polli et al. 2010; Schapiro et al. 2011; Andruniów et al. 2004) in general agreement with the results of this work and previous Raman studies (Kukura et al. 2005; Yan et al. 2004). In addition, two earlier reports (Gascon et al. 2006; Bifone et al. 1997) predict a torsional twist in the $\mathrm{H}-\mathrm{C} 11=\mathrm{C} 12-\mathrm{H}$ moiety of approximately $20^{\circ}$, but subsequent ones (Frutos et al. 2007; Polli et al. 2010; Schapiro et al. 2011; Andruniów et al. 2004) all converge upon a twist of $35^{\circ}-40^{\circ}$. On the other hand, they strongly disagree about the overall twist in the $\mathrm{C} 10-\mathrm{C} 11=\mathrm{C} 12-\mathrm{C} 13$ fragment. The estimated energy stored in the twisted $\mathrm{H}-\mathrm{C} 11=\mathrm{C} 12-\mathrm{H}$ bond varies between ca. $11 \mathrm{kcal} / \mathrm{mol}$ to about $26 \mathrm{kcal} / \mathrm{mol}$ in these publications, in the same range as our calculations.

To summarize, our results do not provide sufficient information to estimate the amount of stored energy through geometrical distortion, except very roughly. The solid-state NMR data is consistent with $\mathrm{H}-\mathrm{C} 11-\mathrm{C} 12-\mathrm{H}$ torsional angles ranging from $0^{\circ}$ (the original cis conformation of rhodopsin, which corresponds to zero torsional strain) to a conformation twisted by $40^{\circ}$ away from trans, which corresponds to a geometrical strain energy of around $80 \pm 12 \mathrm{~kJ} \mathrm{~mol}^{-1}(19 \pm 3 \mathrm{kcal} / \mathrm{mol})$. This upper limit represents $59 \pm 13 \%$ of the stored photon energy, which is $32 \pm 3 \mathrm{kcal} / \mathrm{mol}$. More detailed computations are required to assess the strain energy more accurately.

\section{Conclusion}

A solid state NMR 2Q-HLF experiment was calibrated on a simple model compound (DAF), which shows that in favorable cases the method is able to correctly yield torsional angles within $\pm 5^{\circ}$ (Figs. 5a, 6a). This approach was subsequently applied to a complicated physiological system, thermally trapped bathorhodopsin, the first and very energetic photoproduct of the rod visual pigment rhodopsin, characterized by a poor $\mathrm{S} / \mathrm{N}$ ratio and strongly overlapping resonances of rhodopsin and bathorhodopsin (Fig. 4). In such a case the method is less accurate, and we had to apply a comprehensive extraction and simulation procedure to obtain tangible results. We could deduce that our data indicate for the central $\mathrm{H}-\mathrm{C} 11=\mathrm{C} 1-2 \mathrm{H}$ element of the retinylidene chromophore in bathorhodopsin a deviation of planarity of at least $40^{\circ}$. This result is in very good agreement with previous Raman observations (Kukura et al. 2005; Yan et al. 2004) and is supported by recent quantum-chemical calculations (Frutos et al. 2007; Polli et al. 2010; Schapiro et al. 2011; Andruniów et al. 2004). Such a torsional twist may be responsible for the storage of at least $16 \mathrm{kcal} / \mathrm{mol}$ out of the $32 \pm 3 \mathrm{kcal} / \mathrm{mol}$ of the total photon energy stored in this first photointermediate. Although an anomaly in the chemical shift value of $\mathrm{C} 10$ was at the source of this investigation, the data presented here cannot pin down the origin of the anomaly. However these data can be used as input for a new set of QM calculations that may resolve the issue. The technique here described is quite general and it could be applied to other photo-inducible systems, like, for example, the other intermediates of the rhodopsin photocycle, providing that they may be trapped thermally at temperatures compatible with magic-angle-spinning NMR.

Acknowledgments MC would like to thank Giuseppe Pileio and Marina Carravetta for help during the experimental session; Andreas Brinkmann for advice and suggestions during the setting up of the 2Q-HLF experiment; and Salvatore Mamone, Giuseppe Pileio and Francesco Buda for useful discussions and suggestions. We would also like to thank H. J. M. de Groot, P. Verdegem and J. Lugtenburg for discussions during the early stages of this project. WJdG acknowledges financial support by the European Commission (E-MeP consortium; contract LSHG-CT-2004-504601).

\section{References}

Andruniów T, Ferré N, Olivucci M (2004) Structure, initial excitedstate relaxation, and energy storage of rhodopsin resolved at the multiconfigurational perturbation theory level. Proc Natl Acad Sci USA 101:17908-17913

Bak M, Rasmussen JT, Nielsen NC (2000) SIMPSON: a general simulation program for solid-state NMR spectroscopy. J Magn Reson 147:296-330

Bifone A, deGroot HJM, Buda F (1997) Energy storage in the primary photoproduct of vision. J Phys Chem B 101:2954-2958

Birge RR, Einterz CM, Knapp HM, Murray LP (1998) The nature of the primary photochemical events in rhodopsin and isorhodopsin. Biophys J 53:367-385

Brinkmann A (2001) Dipolar recoupling in magic-angle-spinning nuclear magnetic resonance $\mathrm{PhD}$ thesis, Stockholm University

Carravetta M, Edén M, Johannessen OG, Luthman H, Verdegem PJE, Lugtenburg J, Sebald A, Levitt MH (2001) Estimation of carbon-carbon bond lengths and medium-range internuclear distances by solid-state nuclear magnetic resonance. J Am Chem Soc 123:10628-10638

Concistrè M, Gansmüller A, McLean N, Johannessen OG, MarinMontesinos I, Bovee-Geurts PH, Verdegem P, Lugtenburg J, Brown RCD, DeGrip WJ, Levitt MH (2008) Double-quantum ${ }^{13} \mathrm{C}$ nuclear magnetic resonance of bathorhodopsin, the first 
photointermediate in mammalian vision. $\mathrm{J}$ Am Chem Soc 130:10490-10491

Concistrè M, Gansmüller A, McLean N, Johannessen OG, MarınMontesinos I, Bovee-Geurts PH, Brown RCD, DeGrip WJ, Levitt MH (2009) Light penetration and photoisomerization in rhodopsin studied by numerical simulations and double-quantum solid-state NMR. J Am Chem Soc 131:6133-6140

Creemers A, Kiihne S, Bovee-Geurts P, de Grip WJ, Lugtenburg J, de Groot HJM (2002) ${ }^{1} \mathrm{H}$ and ${ }^{13} \mathrm{C}$ MAS NMR evidence for pronounced ligand-protein interactions involving the ionone ring of the retinylidene chromophore in rhodopsin. Proc Natl Acad Sci 99:9101-9106

de Grip WJ, Daemen FJM, Bonting SL (1980) Isolation and purification of bovine rhodopsin. Methods in Enzymol 67:301-320

Feng X, Lee JK, Sandstrom D, Edén M, Maisel H, Sebald A, Levitt MH (1996) Direct determination of a molecular torsional angle by solid-state NMR. Chem Phys Lett 257:314-320

Frutos LM, Andruniów T, Santoro F, Ferré N, Olivucci M (2007) Tracking the excited state time evolution of the visual pigment with multiconfigurational quantum chemistry. Proc Natl Acad Sci USA 104:7764-7769

Fung BM, Khitrin AK, Ermolaev K (2000) An improved broadband decoupling sequence for liquid crystals and solids. J Magn Reson 142:97-101

Gansmüller A, Concistrè M, McLean N, Johannessen OG, MarınMontesinos I, Bovee-Geurts PH, Verdegem P, Lugtenburg J, Brown RC, Degrip WJ, Levitt MH (2009) Towards a functional interpretation of ${ }^{13} \mathrm{C}$ chemical shifts in bathorhodopsin. Biochim Biophys Acta 1788:1350-1357

Ganter U, Schmid E, Siebert F (1988) The photoreaction of vacuumdried rhodopsin at low temperature: evidence for charge stabilization by water. J Photochem Photobiol, B 2:417-426

Gascon JA, Sproviero EM, Batista VS (2006) Computational studies of the primary phototransduction event in visual rhodopsin. Acc Chem Res 39:184-193

Gaussian 09, Revision A.1, Frisch MJ, Trucks GW, Schlegel HB, Scuseria GE, Robb MA, Cheeseman JR, Scalmani G, Barone V, Mennucci B, Petersson GA, Nakatsuji H, Caricato M, Li X, Hratchian HP, Izmaylov AF, Bloino J, Zheng G, Sonnenberg JL, Hada M, Ehara M, Toyota K, Fukuda R, Hasegawa J, Ishida M, Nakajima T, Honda Y, Kitao O, Nakai H, Vreven T, Montgomery JA Jr, Peralta JE, Ogliaro F, Bearpark M, Heyd JJ, Brothers E, Kudin KN, Staroverov VN, Kobayashi R, Normand J, Raghavachari K, Rendell A, Burant JC, Iyengar SS, Tomasi J, Cossi M, Rega N, Millam JM, Klene M, Knox JE, Cross JB, Bakken V, Adamo C, Jaramillo J, Gomperts R, Stratmann RE, Yazyev O, Austin AJ, Cammi R, Pomelli C, Ochterski JW, Martin RL, Morokuma K, Zakrzewski VG, Voth GA, Salvador P, Dannenberg JJ, Dapprich S, Daniels AD, Farkas Ö, Foresman JB, Ortiz JV, Cioslowski J, Fox DJ (2009) Gaussian Inc., Wallingford

Groesbeek M, Lugtenburg J (1992) Synthesis of doubly and multiply isotopically labeled retinals. J Photochem Photobiol 56:903-908

Honig B, Dinur U, Nakanishi K, Balogh-Nair V, Gawinowics MA, Arnaboldi N, Motto MG (1979) An external point-charge model for wavelength regulation in visual pigments. J Am Chem Soc 101:7084-7086

Hosomi H, Ito Y, Ohba S (1998) Ammonium and isopropylammonium salts of the fumaric acid dianion. Acta Crystallogr Sect C 54:142-145

Kandori H, Maeda A (1995) FTIR spectroscopy reveals microscopic structural changes of the protein around the rhodopsin chromophore upon photoisomerization. Biochemistry 34:14220-14229

Kukura P, McCamant DW, Yoon S, Wandschneider DB, Mathies RA (2005) Structural observation of the primary isomerization in vision with femtosecond stimulated Raman. Science 310:1006-1009

Lai WC, McLean N, Gansmüller A, Verhoeven MA, Antonioli GC, Carravetta M, Duma L, Bovee-Geurts PHM, Johannessen OG, de Groot HJM, Lugtenburg J, Emsley L, Brown SP, Brown RCD, de Grip WJ, Levitt MH (2006) Accurate measurements of ${ }^{13} \mathrm{C}-{ }^{13} \mathrm{C}$ J-couplings in the rhodopsin chromophore by doublequantum solid-state NMR. J Am Chem Soc 128:3878-3879

Levitt MH (2002) Symmetry-based pulse sequences in magic-angle spinning solid-state NMR. In: Grant DM, Harris RK (eds) Encyclopedia of nuclear magnetic resonance: supplementary volume. Wiley, Chichester, pp 165-196

Levitt MH (2008) Spin dynamics. Basics of nuclear magnetic resonance, 2nd edn, Wiley

Marin-Montesinos I, Brouwer D, Antonioli GC, Lai WC, Levitt MH (2005) Heteronuclear decoupling interference during symmetrybased homonuclear recoupling in solid-state NMR. J Magn Reson 177:307-317

McLean NJ, Gansmuller A, Concistre M, Brown LJ, Levitt MH, Brown RCD (2011) Syntheses of ${ }^{13} \mathrm{C}_{2}$-labelled 11Z-retinals. Tetrahedron 67:8404-8410

Nishimura S, Kandori H, Nakagawa M, Tsuda M, Maeda A (1997a) Structural dynamics of water and the peptide backbone around the schiff base associated with the light-activated process of octopus rhodopsin. Biochemistry 36:864-870

Nishimura S, Kandori H, Maeda A (1997b) Transmembrane signaling mediated by water in Bovine Rhodopsin. Photochem Photobiol 66:796-801

Numerical Recipes in C. The art of scientific computing, 2nd Edn, 1992, Cambridge University Press

Palczewski K (2006) G Protein-Coupled Receptor Rhodopsin. Annu Rev Biochem 75:743-767

Paul S, Thakur RS, Goswami M, Sauerwein AC, Mamone S, Concistré M, Forster H, Levitt MH, Madhu PK (2009) Supercycled homonuclear dipolar decoupling sequences in solid-state NMR. J Magn Reson 197:14-19

Polli D, Altoè P, Weingart O, Spillane KM, Manzoni C, Brida D, Tomasello G, Orlandi G, Kukura P, Mathies RA, Garavelli M, Cerullo G (2010) Conical intersection dynamics of the primary photoisomerization event in vision. Nature 467:440-443

Rath P, DeGrip WJ, Rothschild KJ (1998) Photoactivation of rhodopsin causes an increased hydrogen-deuterium exchange of buried peptide groups. Biophys J 74:192-198

Rohrig UF, Guidoni L, Laio A, Frank I, Rothlisberger U (2004) A molecular spring for vision. J Am Chem Soc 126:15328-15329

Schapiro I, Ryazantsev MN, Frutos LM, Ferré N, Lindh R, Olivucci M (2011) Photoisomerizations of rhodopsin and bathorhodopsin are modulated by bond length alternation and HOOP driven electronic effects. J Am Chem Soc 133:3354-3364

Schreiber M, Buss V (2003) Origin of the bathochromic shift in the early photointermediates of the rhodopsin visual cycle: a CASSCF/CASPT2 study. Int J Quant Chem 95:882-889

Schreiber M, Sugihara M, Okada T, Buss V (2006) Quantum mechanical studies on the crystallographic model of bathorhodopsin. Angew Chem Int Ed 45:4274-4277

Vinogradov E, Madhu PK, Vega S (1999) High-resolution proton solid-state NMR spectroscopy by phase-modulated Lee-Goldburg experiment. Chem Phys Lett 314:443-450

Vinogradov E, Madhu PK, Vega S (2002) Proton spectroscopy in solid state nuclear magnetic resonance with windowed phase modulated Lee-Goldburg decoupling sequences. Chem Phys Lett 354:193-202

Wald G (1968) The molecular basis of visual excitation. Nature 219:800-807

Wolfram Research Inc. (2010) Mathematica edition: version 8.0. Champaign, Illinois

Yan ECY, Ganim Z, Kazmi MA, Chang BSW, Sakmar TP, Mathies RA (2004) Resonance Raman analysis of the mechanism of energy storage and chromophore distortion in the primary visual photoproduct. Biochemistry 43:10867-10876 